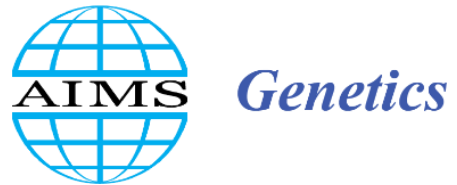

http://www.aimspress.com/journal/Genetics
AIMS Genetics, 5(3): 191.

DOI: 10.3934/genet.2018.3.191

Received: 07 September 2018

Accepted: 12 September 2018

Published: 13 September 2018

\title{
Correction
}

\section{Correction: Time-dependent modulation of FoxO activity by HDAC inhibitor in oncogene-transformed E1A+Ras cells}

\author{
Alisa Morshneva, Olga Gnedina, Svetlana Svetlikova, Valery Pospelov and Maria Igotti* \\ Institute of Cytology, Russian Academy of Sciences, St. Petersburg, Russia \\ * Correspondence: Email: marie.igotti@gmail.com; Tel: +78122973740; Fax: +78122970341.
}

We would like to submit the following correction to our recently published paper [1] due to the incorrect information in the Acknowledgments section by the authors' mistake. The correct Acknowledgments are provided below:

\section{Acknowledgements}

This work was supported by Russian Science Foundation (RSF) under Grant No. 14-50-00068.

The changes have no material impact on the conclusion of this article. The original manuscript will be updated. We apologize for any inconvenience caused to our readers by this change.

\section{References}

1. Igotti M, Gnedina O, Morshneva A, et al. (2018) Time-dependent modulation of FoxO activity by HDAC inhibitor in oncogene-transformed E1A+Ras cells. AIMS Genetics 5: 41-52.

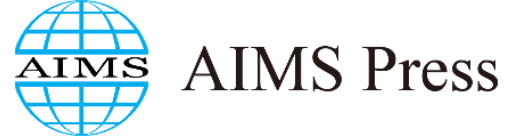

(C) 2018 the Author(s), licensee AIMS Press. This is an open access article distributed under the terms of the Creative Commons Attribution License (http://creativecommons.org/licenses/by/4.0) 